\title{
Polarización y confianza en los medios españoles durante el COVID-19. Identificación de perfiles de audiencia
}

\section{Polarization and trust in Spanish media during the COVID-19. Identification of audience profiles}

\author{
Carmen Maria López-Ricoa, José Luis González-Estebana, Alberto Hernández-Martínez ${ }^{b}$ \\ a Departamento Ciencias Sociales y Humanas, Facultad de Ciencias Sociales y Jurídicas, Universidad Miguel Hernández, España \\ b Departamento de Business Inteligence, Keyrus, Spain
}

\section{Resumen}

Introducción: Durante la crisis sanitaria del COVID-19 la información en los medios de comunicación se ha centrado fundamentalmente en este asunto y el interés de los ciudadanos también ha ido aumentando al respecto. Objetivo: Este trabajo muestra los perfiles de los usuarios españoles en cuanto al consumo de información durante el confinamiento. Metodología: Para ello se ha realizado una encuesta online que fue pionera en el momento de su lanzamiento, lo que nos ha permitido obtener una muestra significativa. La metodología establecida para la gestión de datos se ha llevado a cabo contando usuarios únicos, se han utilizado técnicas de machine learning y el modelo affinity analysis se ha utilizado para descubrir las relaciones de co-ocurrencia entre los elementos. Resultados: De esta forma, hemos podido determinar qué medios han sido más confiables para los ciudadanos a la hora de informarse sobre el coronavirus y si hay una correlación en cuanto a los medios que consumen entre sí. Conclusiones: Definitivamente, se han podido establecer co-ocurrencias entre los usuarios que confían en un medio determinado y otros medios que también son de su confianza y que tienen una tendencia ideológica similar.

Palabras clave: Consumo de medios; COVID-19; desinformación; infodemia; polarización política; información sanitaria.

\begin{abstract}
Introduction: During the COVID-19 health crisis, the information in the media has focused mainly on this topic and the interest of citizens has also increased in this regard. Objective: This work shows the profiles of the Spanish users regarding the consumption of information during confinement. Methodology: For this, an online survey was carried out that was pioneering at the time of its launch, which has allowed us to obtain a significant sample. The methodology established for data management has been carried out by counting unique users, machine learning techniques have been used, and the affinity analysis model has been used to discover co-occurrence relationships in the items. Results: In this way, we have been able to determine which means have been most reliable for citizens when it comes to learning about the coronavirus and whether there is a correlation in terms of the means they consume between them. Conclusions: Definitively, co-occurrence has been established between users who trust a certain medium and other means that are also trusted and they have a similar ideological trend.
\end{abstract}

Keywords: Media consumption; COVID-19; disinformation; infodemic; political polarization; health information. 


\section{Introducción}

a crisis sanitaria del COVID-19 originada en China en diciembre de 2019, se ha expandido de forma global. Con la llegada del primer caso a España, en enero de 2020, la población seguía con el mismo interés las noticias sobre el COVID-19 que el resto de informaciones de actualidad en ese momento. Pero con la declaración del estado de alarma el 14 de marzo de 2020, la atención de los ciudadanos sobre el tema ha ido creciendo rápidamente y con ello, la cantidad de información que los medios han ofrecido sobre el tema.

Esta pandemia ha cambiado las estructuras sociales y la forma en la que nos informamos está desarrollándose en un contexto socio-económico nuevo. Los peligros de la desinformación, sobre todo causada por la infoxicación o infodemia están siendo visibilizados a través del papel que las redes sociales están teniendo durante el confinamiento. Encontrar información veraz y que nos ofrezca un análisis riguroso del contexto en el que vivimos es, en ocasiones, una tarea complicada.

El conflicto entre verdad y política viene de muy lejos. Aunque la democracia no tiene por objetivo alcanzar la verdad, sino la gestión de lo público con la contribución de la ciudadanía, la información y las narrativas compartidas son una precondición del discurso democrático. Sin embargo, la digitalización del espacio público ha añadido complejidad a nuestra relación con la verdad (Innerarity \& Colomina, 2020, p. 8).

La información de calidad es fundamental para la creación de la Opinión Pública y el conocimiento del entorno en el que vivimos y en una situación como la que estamos viviendo por el COVID-19, es fundamental que los ciudadanos estén bien informados. Actualmente tenemos múltiples canales y opciones mediáticas donde hacerlo y a priori, una amplia oferta nos lleva a pensar en un mayor grado de pluralismo informativo. A pesar de que el ecosistema mediático español se ha transformado, sufriendo una importante atomización a partir del bienio 2007-2009 cuando surgió el primer medio nativo digital profesional, Soitu (González-Esteban, 2010), esta evolución nos indica que el papel de intermediarios de los medios se ha visto reducido por las redes sociales, un canal donde la desinformación penetra fácilmente por el gran volumen de contenidos generados y la variedad de sujetos que interpretan la realidad (Innerarity \& Colomina, 2020).

Por otro lado, no podemos obviar que los medios siguen teniendo intereses económicos y partidistas a los que están sometidos directa o indirectamente, por lo que este estudio pretende conocer el nivel de confianza de los ciudadanos durante el confinamiento provocado por el COVID-19 y si se observan patrones relacionados con las líneas editoriales de dichos medios.

\section{La polarización ideológica en el sistema mediático español}

El estudio de Hallin y Mancini (2008) nos ofrece una clasificación de los sistemas de medios occidentales del siglo XX. Los autores establecieron distintas variables de análisis que les permitiera diferenciarlos y/o agruparlos por países. Estas se centraron fundamentalmente en la circulación de la prensa y la estructura de los mercados; la vinculación con los partidos políticos y organizaciones civiles (lo que ellos llaman paralelismo político); el nivel de profesionalidad y el grado de intervencionismo del Estado. Así lograron establecer tres modelos diferenciados: Pluralista Polarizado (o del Mediterráneo); Democrático Corporativo (o del centro o del norte de Europa) y Liberal (o del Atlántico Norte).

El sistema de medios en España forma parte del Modelo Pluralista Polarizado o del Mediterráneo, que se caracteriza por tener un paralelismo político considerablemente alto, ya que el sistema mediático está fuertemente integrado con los partidos políticos e instituciones sociales como sindicatos o grupos religiosos. Además, el intervencionismo estatal es alto y la profesionalización no alcanza los niveles de los países del norte de Europa o del sistema de medios anglosajón (Modelo Liberal).

Tras la llegada de la democracia a España, los ciudadanos han convivido con las distintas líneas editoriales de los principales medios. Casos como: la relación entre Jesús de Polanco (PRISA) y los gobiernos del Partido Socialista Obrero Español (PSOE) con Felipe González; el tratamiento favorable de El Mundo al proyecto popular de José Ma Aznar; o las licencias que Esperanza Aguirre, del Partido Popular (PP) y presidenta de la Comunidad de Madrid, concedió a medios de una línea ideológica identificada como centro-derecha (COPE, Libertad Digital, Arzobispado de Madrid, El Mundo, Onda Cero, Intereconomía, Kiss TV, Canal 7 y TV Digital de Madrid (controlada por Enrique Cerezo, presidente del Club Atlético de Madrid) mientras que otras empresas de comunicación identificadas con una ideología de izquierdas o centro-izquierda quedaron fuera, como PRISA, Prensa Ibérica y Grupo Zeta (De Miguel \& Pozas, 2009, p. 47).

Partimos de la clasificación de Reig (2011) y el Informe sobre la profesión periodística en España de 2010 para conocer como los ciudadanos perciben la posición partidista de los principales medios nacionales (Humanes, Martínez, \& Saperas, 2013) (tabla 1).

En España tenemos "un periodismo orientado al comentario, y vehiculado a través de las tertulias 
radiofónicas y televisivas, en el que los periodistas actúan como representantes de posiciones ideológicas coincidentes con las de los partidos políticos" y "los ciudadanos perciben que el sesgo político de las noticias va en aumento" (Farias y Roses, 2009, citado en Humanes, 2014, p. 782).

Diversos estudios sobre exposición selectiva en España en varias épocas, han establecido paralelismos entre la lectura de ciertas cabeceras y el voto. Es el caso de Comparative National Elections Project (1993), que mostraba la relación entre El País y el PSOE, el $A b c$ con el PP y El País y El Mundo con Izquierda Unida (IU) (Gunther, Montero y Wert, 1999, citado en Humanes, 2014, p. 782-783). 0 que los lectores de El País preferían Televisión Española (TVE) y los del PP Antena 3 (Alcalde-Villacañas, 2003, citado en Humanes, 2014, p. 782-783).

Del mismo modo, Roses (2010) reveló que la credibilidad informativa de un medio aumenta si hay una identificación con la línea editorial del mismo, es decir, "la confianza en los medios se ve menoscabada cuando el individuo se informa a través de varios de ellos" (citado en Humanes, 2014, p. 782-784).

Asimismo, la audiencia puede seleccionar los medios de comunicación que prefiera, basándose en sus preferencias políticas, lo que se conoce como exposición selectiva partidista. La literatura científica ha documentado la relación entre la exposición selectiva partidista y la polarización política y encontramos resultados transversales que muestran evidencias la relación entre ambas en ambos sentidos: la exposición selectiva partidista conduce a la polarización y la polarización conduce a una exposición selectiva partidista (Jomini Stroud, 2010).

Esta politización se ha dado también en la corporación pública de Radio Televisión Española (RTVE), "fue patente en los gobiernos de Suárez, Calvo Sotelo, González y Aznar" aunque con el gobierno de Zapatero se introdujeron cambios legislativos que lograron impulsar al ente público a una posición menos politizada (De Miguel \& Pozas, 2009, p. 47).

Es el caso de la Ley 17/2006 de la radio y televisión de titularidad estatal, dotó al ente de mecanismos para alcanzar un grado mayor de independencia, por ejemplo dando al Parlamento la competencia para el nombramiento del Presidente y demás miembros del Consejo de Administración por mayoría cualificada, o con la creación de los Consejos de Informativos como órganos internos de participación y control profesional para velar por la independencia editorial, la objetividad y veracidad de los contenidos difundidos la corporación pública. También hacía referencia a la importancia de la independencia económica de RTVE, estableciendo un modelo de financiación mixta (combinando ingresos de los Presupuestos Generales del Estado, con los derivados de la publicidad) bajo el principio de equilibrio presupuestario y que posteriormente la Ley 8/2009 de financiación de la Corporación de Radio y Televisión Española concretaba en un modelo que eliminaba la financiación por publicidad.

Durante esta época, es indudable que el prestigio de la radiotelevisión pública española llegó a lo más alto. Bajo la dirección de Fran Llorente en los Servicios Informativos de TVE, sus programas y sus profesionales recibieron más de 200 premios, entre ellos el TV News Awards 2009 para el Telediario Segunda Edición como mejor informativo y en 2010 el Global Peace Award, por la cobertura de los conflictos internacionales (The New Tech Observatory, n.d.).

Sin embargo, con la llegada al gobierno de Mariano Rajoy (PP) se modificó la normativa para que la elección del Consejo de Administración de RTVE fuese por mayoría simple en segunda vuelta, limitando de nuevo la necesidad de consenso entre todas las fuerzas políticas (López-Rico, 2012, p. 203). Actualmente, el ente público se encuentra bloqueado desde hace dos años, por la paralización del concurso público a través del cual se configura el Consejo de Administración (Boix, de la Sierra, Guichot, \& Manfredi, 2020).

Estudios como el realizado por Humanes, revelan que "los individuos cambian su fuente de información cuando detectan que la línea editorial del medio de comunicación se ha modificado" confirmando "que las predisposiciones políticas intervienen en la fidelización de nichos de audiencia" (2014, p. 795). Esto también se percibe en la corporación pública española, pues la audiencia puede consumirla 0 dejar de hacerlo, dependiendo de quién gobierne.

Tabla 1. Percepción de los ciudadanos sobre la tendencia partidista de los medios.

\begin{tabular}{|c|c|}
\hline PSOE & PP \\
\hline El País & El Mundo \\
\hline SER & Abc \\
\hline RNE & La Razón \\
\hline TVE & COPE \\
\hline La Sexta & Onda Cero \\
\hline Telecinco & Telecinco \\
\hline & Antena 3 \\
\hline
\end{tabular}

Elaboración propia. Fuente datos: Humanes et. al. 2013. 
Tratamiento informativo durante otras crisis sanitarias en España

En los últimos años hemos vivido diversas pandemias como el VIH, la gripe aviar, el SARS, el virus Zika, el Ébola y el COVID-19 es una más, y es previsible que no será la última. La diferencia entre todas ellas ha sido el nivel de interés mediático sobre las mismas. El COVID-19 ha sido especialmente seguido por los medios de comunicación principalmente por la velocidad de propagación a nivel mundial, especialmente en países desarrollados con gran peso en la economía global, especialmente China y EE.UU.

En 2003 el Síndrome Respiratorio Agudo Grave (Severe Acute Respiratory Síndrome, SARS) infectó a más de ocho mil personas en 30 países del mundo, dejando a más de ochocientos fallecidos, por lo que se consideró la primera enfermedad infecciosa grave del siglo XXI.

En este caso, según Rosich, Morales y Bosch, la información provenía de fuentes unificadas y había una saturación sobre el tema pues "las características tan especiales de la neumonía atípica convirtieron la epidemia en material periodístico de primera línea" (2007, p.23). Sin embargo, los ciudadanos no llegaron a conocer aspectos fundamentales sobre la enfermedad pues en opinión de los autores, los medios perdieron el interés sobre el SARS, de modo que la información científica que se obtuvo con posterioridad al brote no fue difundida en general. Del mismo modo, los autores destacan que la prensa no trató en profundidad la información sobre la red internacional de centros e investigadores que identificó el posible origen del SARS (Rosich, et. al., 2007, p.23).

Para Rosich, Morales y Bosch, "esta crisis puso en evidencia la necesidad de una buena interacción entre periodistas y científicos para una correcta divulgación científica". Destacan una relación con algunas incompatibilidades ya que "ciencia y periodismo, siguen trabajando a ritmos diferentes lo cual condiciona la adecuada divulgación de la información a los profesionales sanitarios y al ciudadano" (Rosich, et. al., 2007, p.23). Algo que vuelve a ponerse de manifiesto en la crisis del COVID-19 y que además se afectada por los bulos que intentan desinformar a la población tanto con aspectos sanitarios de la pandemia (remedios caseros para curar el virus, medidas de protección no científicas...) como en los aspectos de control de la población y medidas en general de la Administración pública.

Los valores noticia incluyen la proximidad como una característica esencial para que un hecho sea noticioso, en este caso, la llegada masiva del virus a nuestro país ha influido en la cobertura del acontecimiento.

\section{Deontología informativa durante una epidemia}

El interés de los ciudadanos en el COVID-19 ha aumentado a la par que el virus se extendía y los medios dedicaban más tiempo a este asunto. Sin embargo, las noticias han estado centradas en los países del norte, dejando al margen 0 con un tratamiento residual, la cobertura en África, sudeste asiático o Suramérica.

Según Ecobox el interés por el COVID-19 ha ido aumentando. En España, el 25 de febrero, en solo 48 horas, compartir noticias sobre coronavirus aumentó de un $4 \%$ a un $14 \%$. El 10 de marzo, se superó a Italia con niveles de récord, un $22 \%$ de las noticias del día compartidas eran sobre el coronavirus y el 12 de marzo fue un día sin precedentes en España, el 37\% de las noticias compartidas en el día fueron sobre el COVID-19 (Echobox, 2020). Estos datos revelan la importancia de ofrecer una información ética, veraz y rigurosa en temas tan sensibles como una pandemia de este calibre.

En un reciente estudio comparativo sobre la confianza en la cobertura mediática antes y después del confinamiento en EE.UU., se observa como "el aumento del consumo de noticias vino acompañado de un ligero incremento de la valoración positiva de la cobertura mediática, asociada a la credibilidad". Sin embargo, la investigación apunta que "a pesar de esto, los datos sugieren que el incremento de consumo de noticias sobre el Coronavirus no se tradujo en un aumento significativo de la confianza hacia los medios" (CaseroRipollés, 2020, p. 7).

Para Arias Bohigas el tratamiento ético de la información durante una epidemia es fundamental para la gestión de la misma, pues "la información epidemiológica detallada puede ser usada con fines perversos (...), pero en contraste la información limitada conduce al desconocimiento de los profesionales y ciudadanos sobre los riesgos a los que pueden estar enfrentándose" (2009, p. 490).

La relación entre periodistas y científicos es fundamental, pues la mitad de las noticias médicas en prensa generalista son noticias médicas (Bauer, 1998 citado en Casino, 2015) y la epidemiología es uno de los temas que afectan en gran medida a la sociedad, de modo que hay un gran interés informativo sobre ello. La epidemiología trata aspectos relevantes para nuestra salud como "el ejercicio físico, la dieta, la contaminación, el urbanismo, la democracia, la televisión, el ruido, el número de hijos, la educación, la delincuencia, los servicios sociales, el tamaño de las ciudades, la calidad del agua o la amistad" (Casino, 2015, pp. 1-2).

Para informar sobre epidemiología se necesitan 
unos conocimientos mínimos para poder interpretar los resultados de los estudios y estadísticas sanitarias, así como la terminología y conceptos que nos permitan informar con veracidad y sin imprecisiones que puedan llevar a los ciudadanos a un clima de sobreinformación o sensacionalismo. Gonzalo remarca que los errores y distorsiones más frecuentes están relacionadas "con las condiciones y las exigencias del ejercicio periodístico, y en particular con la complejidad de la materia informativa, la calidad de las fuentesyla presión del tiempoy otros factores periodísticos" (Casino, 2015, p.3). En general plantea los siguientes problemas en la información epidemiológica: dificultades de interpretación de bioestadística; confusión sobre el concepto de causalidad; desconocer el diseño y confianza de los estudios; dificultad para localizar fuentes confiables; redacción de titulares que no transmiten la incertidumbre que siempre está presente en los estudios científicos (Casino, 2015, pp. 3-6).

Para Miquel Porta, hay muchas maneras de etiquetar a los estudios epidemiológicos que "tienen poco que ver con la ciencia, y mucho que ver con la sociología de la ciencia, la construcción social del conocimiento, las costumbres y prejuicios, la psicopatología humana, el corporativismo y la ignorancia". Y añade que, "Io mismo vale para la propia querencia a etiquetar, compartimentar, encumbrar, denostar... El periodismo debería y podría hablar más de cómo estas pulsiones operan en la ciencia" (Porta, 2015, p. 26).

El lenguaje también es fundamental, "las definiciones de las enfermedades y de sus causas no son inmutables: pueden cambiar según el contexto social". Algunos ejemplos de cambio en definiciones o causas de condiciones se han dado en términos como "esquizofrenia, psicosis, neurosis, nervios, violencia de género, (...) Los cambios en las definiciones de las enfermedades y de sus causas son, de nuevo, cuestiones científicas de considerable atractivo social y, por tanto, periodístico" (Porta, 2015, p. 30).

Algunas recomendaciones que pueden ayudar mejorar la información sobre estos temas se reducen a: acceder a fuentes adecuadas e independientes a las que realizar preguntas que permitan a la sociedad conocer los avances y contexto de la investigación; evitar los tecnicismos para acercar la información a la ciudadanía; intentar llevar la iniciativa en cuanto a la selección de temas, de forma que podamos ofrecer los más significativos a la audiencia; mantener cierto escepticismo para no caer en la información científica que llega a través de notas de prensa de posibles fuentes interesadas; ser cautelosos a la hora de transmitir un estudio, asegurándonos de entender los resultados y aportando el máximo contexto a la hora de explicar sus implicaciones sociales (Casino, 2015, pp. 6-8).

Necesitamos acudir a fuentes fiables para contrastar "cifras acerca de la magnitud, la distribución o el impacto de los fenómenos relacionados con la salud sobre los que se informa, ya que estos no son neutros y contribuyen poderosamente a generar un estado de opinión en los lectores". Para ello buscaremos fuentes que nos proporcionen datos de interés sanitario de dos tipos fundamentalmente: información epidemiológica/ estadísticas y resultados de estudios. Contrastar esta información es una tarea importante y ardua, puesto que hay un gran volumen de informaciones sanitarias y no hacerlo correctamente "contribuye a la disparidad de cifras y datos epidemiológicos que a menudo ofrecen los medios de comunicación, lo que a su vez contribuirá a magnificar o minimizar la importancia real de los problemas y sus consecuencias". A este fenómeno se le conoce en medicina como disease mongering, "a través del cual se crean enfermedades o se exageran situaciones fisiológicas asociándolas con posibles sufrimientos 0 patologías, habitualmente con fines comerciales" (Alonso \& Urrutia, 2015, p. 57).

En esta línea, la Organización Panamericana de la Salud (OPS) junto a la Organización de la Salud (OMS), han editado una guía para periodistas, que incluye un apartado específico para luchar contra los rumores y las teorías, recomendando especialmente: la consulta de fuentes oficiales y acreditadas, evitando fuentes no acreditadas que generen ruido o creen alarmismo y evitar repetir informaciones sin base científica (OPS, 2020).

\section{Objetivo}

Esta investigación tiene como objetivo buscar la correlación como una aproximación para conocer el tipo de medios en los que han confiado los ciudadanos para informarse durante el confinamiento por el COVID-19, así como relacionarlos entre ellos, de forma que podamos establecer unos perfiles de usuario tipo. De igual modo, se pretende conocer la influencia de la polarización política, agudizada durante la presente crisis sanitaria, y su afectación al consumo de medios.

Para ello determinamos las siguientes variables dependientes:

- Valoración de la confianza en los distintos medios españoles para informarse sobre el COVID-19.

- Preferencia de consumo de medios extranjeros durante la cuarentena por COVID-19.

En cuanto a las variables independientes hemos establecido 3 sociodemográficas: 
- Edad: 18-30; 31-40; 41-50; 51-65; 66-80; Mayor de 80. - Nivel de estudios: Sin estudios; Graduado escolar-ESO; Bachiller; Licenciado - Graduado; Máster; Doctorado.

- Lugar de residencia.

- Confianza en distintas plataformas para informarse: Televisión; Radio; Prensa Escrita (papel y digital); Redes Sociales (Facebook, Twitter, Instagram, TikTok, etc.); Internet (páginas web que no son medios de comunicación); Mensajería privada (WhatsApp, Telegram, Line, etc.); Plataformas de vídeo (YouTube, Vimeo, etc.); Otras.

- Percepción sobre la información rigurosa, veraz y ética sobre el coronavirus en: cadenas de radio, cabeceras de prensa y canales de televisión españoles.

\section{Metodología}

Para ello hemos realizado una encuesta online, compuesta por 30 preguntas en las que de forma anónima los ciudadanos respondían en tres bloques diferenciados: datos demográficos (como su edad, nivel de estudios, lugar de residencia); consumo de medios (tipo de canal y nombres de medios en los que confiaban para informarse sobre el COVID-19); uso de redes sociales y WhatsApp. En esta publicación nos centraremos solo en las secciones relacionadas con el consumo de medios y sus características demográficas.

La muestra obtenida es de $(\mathrm{N}=1708)$ respuestas válidas con usuarios mayores de 18 años de edad, siendo excluidos los mayores de 80 cuando utilizamos esta variable independiente ya que no se ha conseguido una muestra $(n=5)$ representativa para que este grupo sea significativo en los resultados obtenidos. En este trabajo, también se ha filtrado el lugar de residencia solo en España, ya que estos encuestados tienen acceso a los medios españoles al completo y no solo a las versiones internacionales. Obteniendo respuestas de todas las comunidades y ciudades autónomas españolas.

En la opción "Otras" de la pregunta sobre en qué canales de comunicación confías para informarte sobre el coronavirus, no se han identificado respuestas válidas a la pregunta formulada, por lo que se han excluido. Se han tenido en cuenta aquellos que han referido que no confiaban en ninguno de los canales mencionados como respuesta válida, pero no se visualizan en el gráfico ya que supone $1 \%$ en los distintos grupos de nivel de estudios.

El formulario se difundió durante el periodo de confinamiento comprendido del 3 al 10 de abril de 2020, a través de distintos organismos y asociaciones, redes sociales, email y WhatsApp. Cabe señalar que esta encuesta fue pionera al comienzo del confinamiento, lo que nos ha permitido obtener un número de respuestas amplío. Los datos obtenidos se han procesado con el programa Alteryx y su visualización posterior se ha realizado con Tableau.

La metodología establecida para la gestión de los datos se ha realizado mediante el conteo de usuarios únicos, que resulta imprescindible sobre todo para las preguntas con respuesta múltiple. Para ello se han creado una base de datos relacional que se compone de una tabla principal, donde la clave primaria es ID de cada encuestado, y otras tablas secundarias para las preguntas con respuesta múltiple. Éstas se corresponden con el ID del encuestado, a través de relaciones de uno a muchos (1:n).

Para la matriz de asociación se han utilizado técnicas de machine learning combinando las respuestas de los encuestados a las preguntas Q10, Q11 y Q12 del cuestionario sobre qué programas informativos de televisión/radio/diarios consideraban que estaban ofreciendo una información más rigurosa, veraz y ética sobre el coronavirus.

Se ha utilizado el modelo de affinity analysis que permite descubrir relaciones de co-ocurrencia en los ítems (medios de comunicación) seleccionados por los usuarios en dichas preguntas. Por lo que nos dará como resultado correlaciones y no causalidad.

Para las combinaciones de ítems se han creado reglas de asociación con un algoritmo a priori, el cual identifica los ítems de forma individual por su frecuencia en la base de datos y crea combinaciones de mayor tamaño, cuando ese conjunto de datos tiene una frecuencia suficiente en la propia base de datos.

\section{Resultados}

Para responder a la primera variable dependiente, como podemos observar en la figura 1, el nivel de educación muestra diferencias en cuanto a la confianza que los ciudadanos tienen sobre distintos canales de información.

Se aprecia como el $69 \%$ de los encuestados sin estudios o con Estudios Secundarios Obligatorios (ESO) confían mayoritariamente en la televisión en detrimento de otros canales. El patrón de los usuarios con Bachiller se asemeja al perfil anterior con un ligero aumento de confianza en la prensa.

Por otro lado, los encuestados que tienen un nivel de estudios superiores confían más en la prensa, situándose por encima de la media. En el caso concreto de los licenciados/graduados y doctores, se aprecia igualmente una confianza mayor que el resto en la radio y destaca la 
confianza de los doctores y maestros en webs que no son medios de comunicación profesionales y en mensajería privada.

En cuanto a la edad, no se advierten diferencias notables en televisión, donde todos confían para informarse del COVID-19 por igual, pero sí encontramos una confianza mayor en la radio por los grupos a partir de 41 años. Sin embargo, esta situación se produce a la inversa en las redes sociales, donde los usuarios de 18 a 40 años confían por encima de la media y a parir de 41 años esta confianza cae progresivamente.

Otro resultado relevante muestra como hasta los 40 años la confianza en la prensa, ya sea online o papel, es ligeramente superior a la media (58\%) pues un $62 \%$ de los encuestados de entre 18 y 40 han señalado estos medios como confiables para informarse del COVID-19. El resto de grupos se sitúa entre un $58 \%$ y un $53 \%$.

Por lo que respecta a plataformas de videos los mayores de 66 años tienen una confianza testimonial mientras los usuarios de 31 a 40 años son los que más confían en estos canales para informarse sobre el coronavirus.

Es importante destacar que en cuanto a plataformas de mensajería privada son los mayores de 66 años los que más confianza tienen este canal, con un $13 \%$ de este sector poblacional, les siguen los ciudadanos de 51-65 y de 41-50. Los encuestados de entre 18 y 40 son los que menos confían en estos canales para informarse sobre el COVID-19.

Por otro lado, como podemos ver en la figura 3, gracias al análisis de afinidad, hemos podido observar las correlaciones entre distintas televisiones, radios y periódicos españoles. Podemos ver las percepciones de los encuestados con respecto a estos medios y si ofrecían una información más rigurosa, veraz y ética sobre el coronavirus.

La matriz distribuye los porcentajes horizontalmente, es decir, en la línea de TVE vemos que el $38 \%$ de los que creen que la televisión pública ofreció información de calidad sobre el COVID-19 también valoran en este sentido a La Sexta.

Podemos distinguir como hay una correlación en la percepción de los encuestados entre aquellos medios con una tendencia ideológica más de izquierdas o de derechas, viendo agrupaciones significativas entre ambos posicionamientos. Se consideran dichas ideologías determinadas por sus propias líneas editoriales, así como hemos apuntado anteriormente, con la percepción de los ciudadanos según el Informe sobre la profesión periodística en España (2010, citado en Humanes, et.al., 2013) y que hemos referido en la tabla 1.

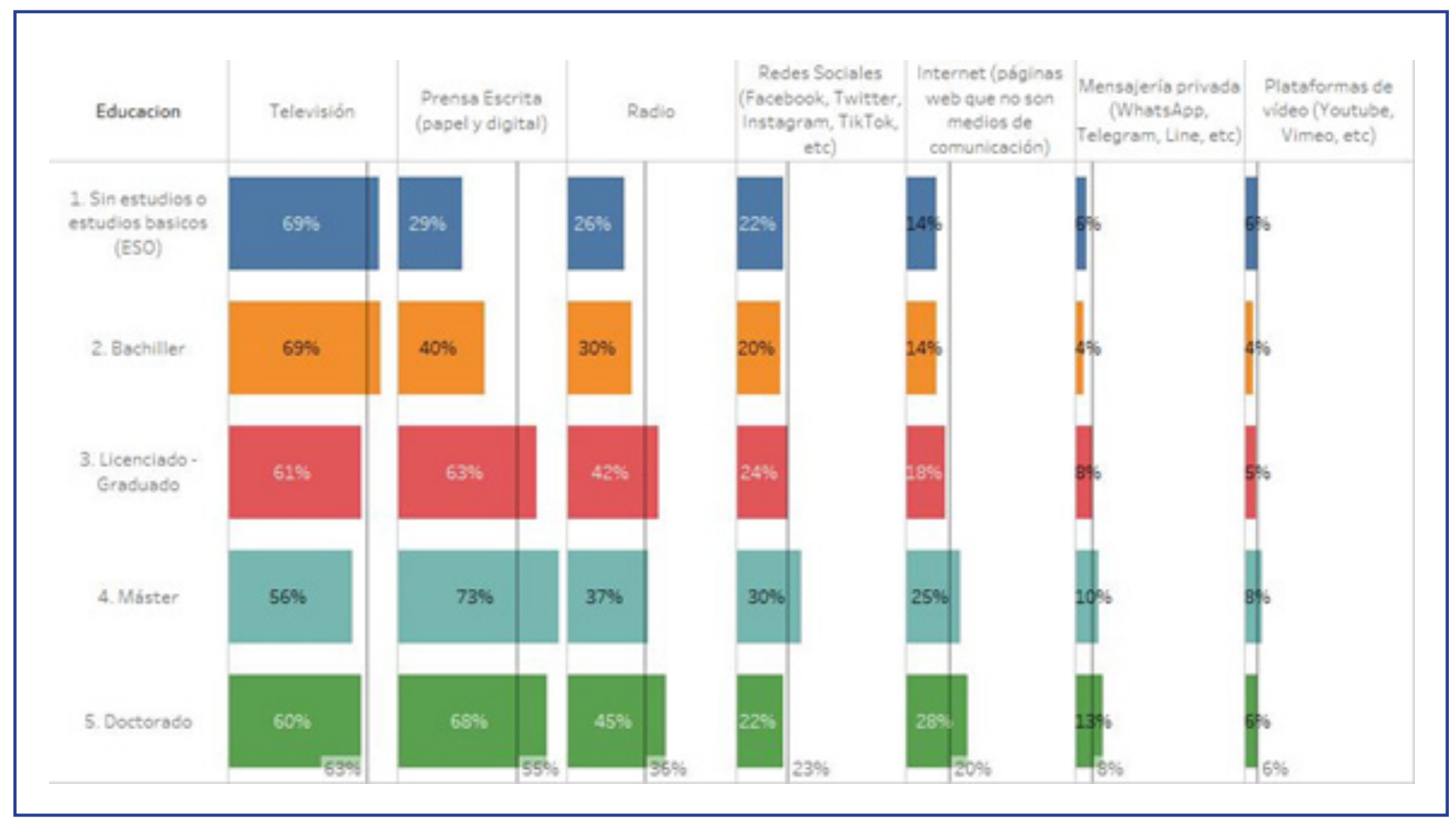

Figura 1. Confianza en canales de información por nivel estudios. Fuente: Elaboración propia. 


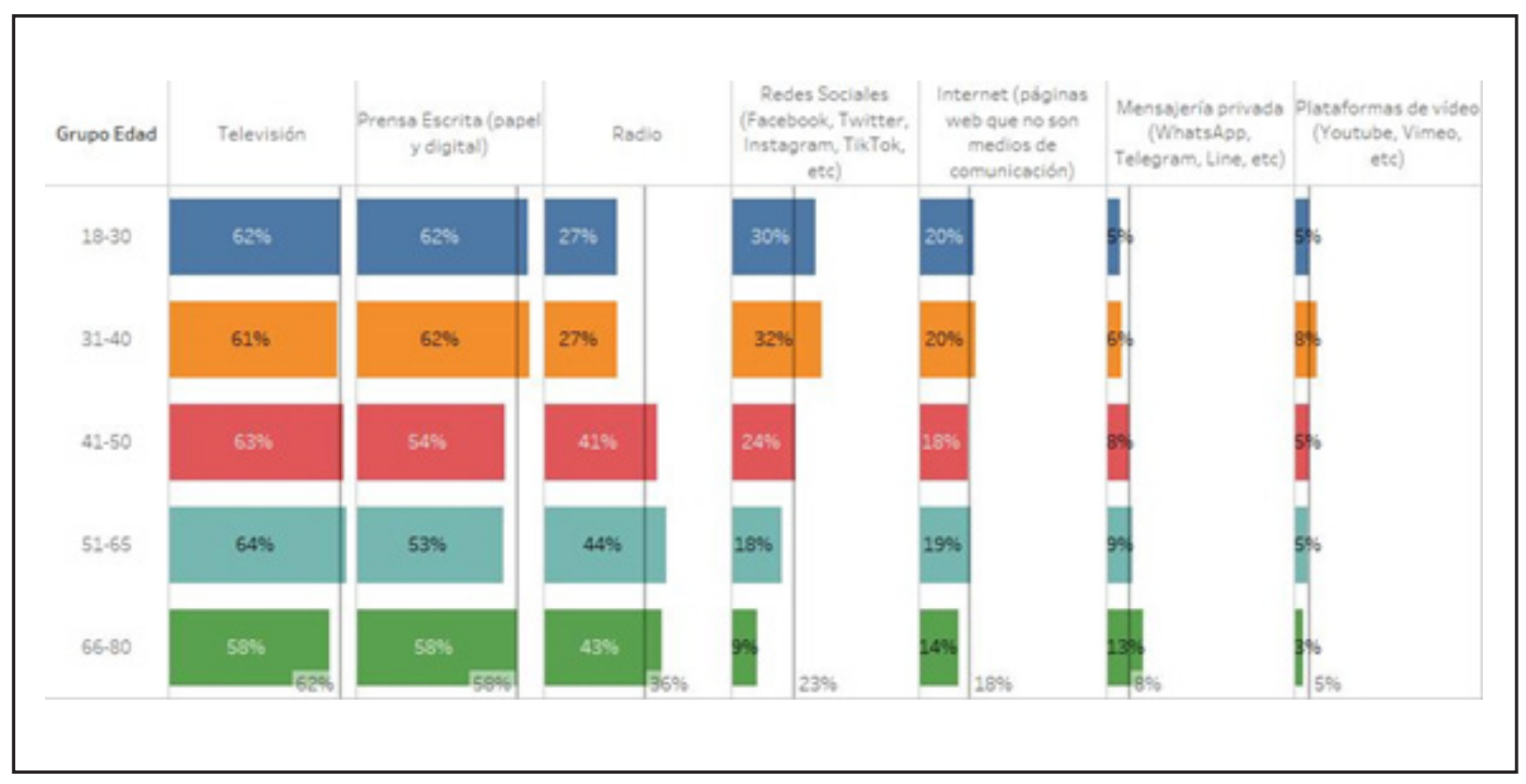

Figura 2. Confianza en canales de información por edades. Fuente: Elaboración propia.

Co-ocurrencias con la corporación pública de RTVE

En cuanto a los medios públicos, vemos claramente como la confianza en TVE es superior entre los que confían en medios con una línea editorial de centro-izquierda como Eldiario.es (61\%), El País (57\%) y la cadena SER $(60 \%)$, superando el $50 \%$. Mientras que los que confían en medios más de centro-derecha como El Español (35\%), El Mundo (33\%), La Razón (31\%), Abc (30\%), no alcanzan el $40 \%$. Es especialmente reseñable el caso de los que confían en la información de OkDiario, de los cuales solo el 19\% confían en TVE.

En el caso de la radio, el $31 \%$ de los que confían en Eldiario.es y el $28 \%$ de los que confian en El País, lo hacen en Radio Nacional de España (RNE).

En este sentido, los resultados nos plantean una coocurrencia fuerte entre la prensa de centro-izquierda y la televisión pública, a pesar de que partimos de la premisa de que el ente de RTVE no se identifica editorialmente con ninguna ideología política. Aunque como hemos expuesto anteriormente, en España la radiotelevisión pública se ha visto politizada, en mayor o menor grado, por los distintos partidos que han gobernado. Un claro ejemplo fue Radio Televisión Valenciana (RTVV), con Canal 9 como una de las televisiones autonómicas más castigadas por la intervención política, lo que propició una gran pérdida de pluralismo político (López-Rico, 2012) y que acabó siendo denunciado públicamente por los propios profesionales del medio.

Apreciamos como hay una co-ocurrencia fuerte entre las televisiones y radios autonómicas, un $50 \%$ de los que confían en radios autonómicas, afirma que lo hacen también en las televisiones autonómicas.

Patrones identificados en los grupos de comunicación

Por lo que respecta a medios privados, se aprecia un patrón de confianza en los medios audiovisuales de un mismo grupo de comunicación, por ejemplo: el $41 \%$ de los que confían en Onda Cero, lo hacen en Antena 3 o el $66 \%$ de los que confían en la cadena SER confían en EI País. Encontramos la excepción en el grupo Mediaset, ya que solo el $23 \%$ de los que confían en Telecinco lo hacen en Cuatro y viceversa solo un 33\%.

En el caso de la corporación pública, también se observa este comportamiento, ya que el $74 \%$ de los que confían en RNE confían en TVE. 


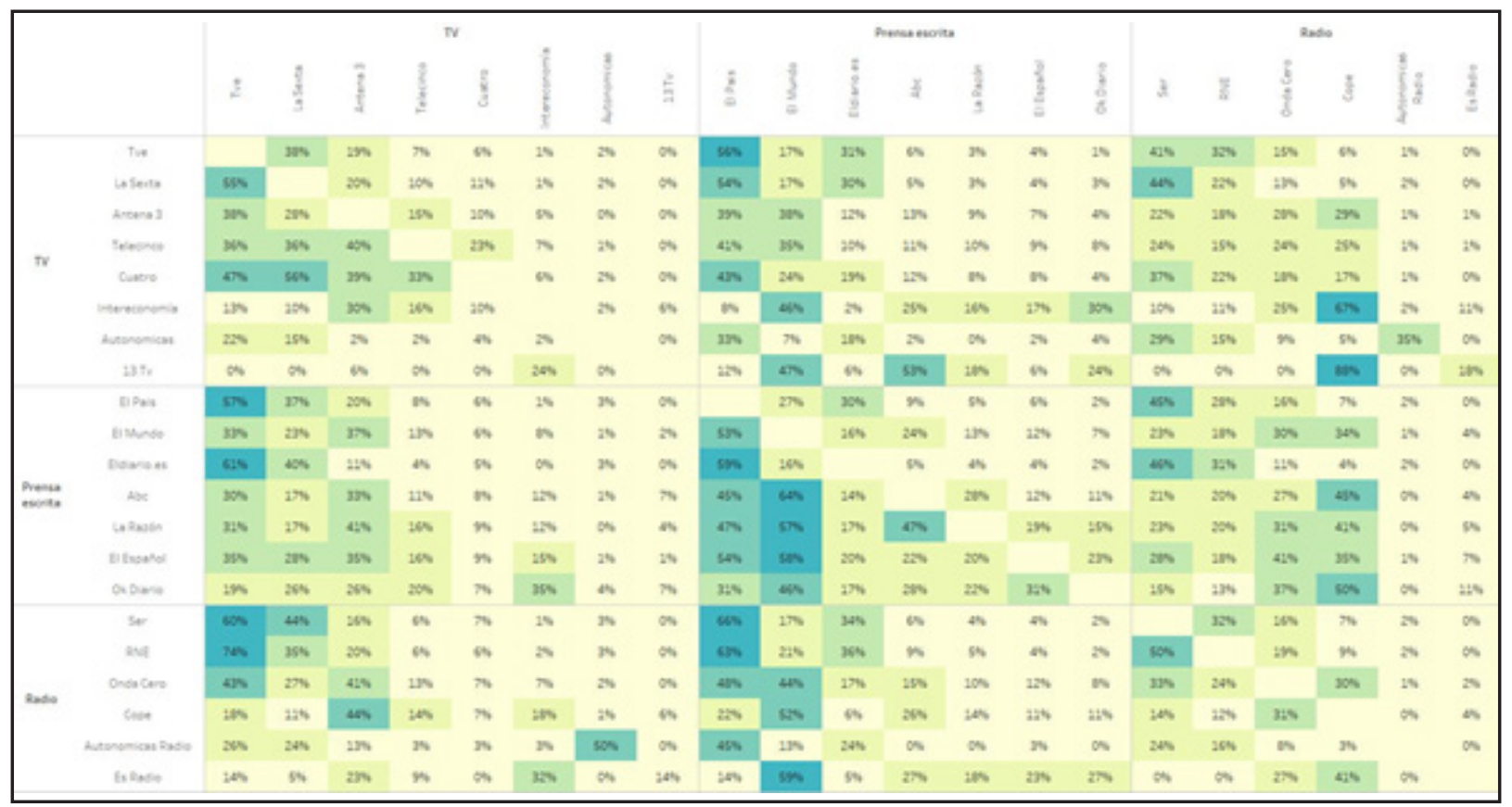

Figura 3. Combinación de medios en los que confían. Fuente: Elaboración propia.

\section{Co-ocurrencia entre radios y prensa}

En cuanto a las radios, también se aprecian los patrones de agrupamiento ideológico. El $66 \%$ de los que confían en la SER confían en la calidad de El País, y el $34 \%$ de los que confían en la SER, lo hacen en Eldiario.es. A la inversa la co-ocurrencia existe igualmente, ya que el $45 \%$ de los que confían en El País y el $46 \%$ de los que lo hacen en Eldiario.es también lo hacen en la SER.

Por otro lado, más de la mitad de los que confían en la información de EsRadio (59\%) y en la cadena COPE (52\%), confían en la información de El Mundo. Un 27\% de los que afirmaron que la información de EsRadio era veraz, confían en OkDiario; un $26 \%$ de los que confían en la COPE, muestran su confianza en la calidad informativa de $A b c$ y un $23 \%$ de los que valoran positivamente EsRadio también lo hacen de El Español.

Si lo vemos desde el punto de vista de la prensa, se confirma la tendencia, pues el $50 \%$ de los que confían en OkDiario, el $45 \%$ de $A b c$ y el $41 \%$ de La Razón, confían en la COPE. Siguiendo con la tendencia, el $41 \%$ de los que consideran ética y veraz la información de El Español y el $37 \%$ de OkDiario, confían en Onda Cero.

Co-ocurrencia entre televisiones y prensa

El patrón de agrupamiento ideológico se observa del mismo modo entre las televisiones y la prensa. Vemos que el $41 \%$ de los que consideran La Razón como un medio de información veraz y ética sobre el COVID-19 creen que lo es también Antena 3 y un $35 \%$ de los que consideran un medio riguroso a OkDiario, piensan lo mismo de Intereconomía.

En el sentido opuesto ideológicamente hablando, se advierte como el $40 \%$ de los que confían en Eldiario.es y el $37 \%$ de El País, confían en La Sexta.

Ala inversa la co-ocurrencia prevalece en este sentido. Podemos apreciar como el $54 \%$ de los que confían en La Sexta y el $43 \%$ de Cuatro, lo hacen en El País también. Además, el $30 \%$ de los encuestados que afirman confiar en La Sexta, muestran su confianza en la información de Eldiario.es.

En el grupo de cabeceras de centro-derecha, los encuestados que muestran confianza en Intereconomía y 13Tv tienen los valores más altos de co-ocurrencias con los diarios: El Mundo, OkDiario, Abc, La Razón y El Español principalmente. Los resultados específicos indican que el $46 \%$ de los que confían en Intereconomía y el $47 \%$ de $13 \mathrm{TV}$, lo hacen en EI Mundo; el $53 \%$ de los que confían en $13 \mathrm{Tv}$ y el $25 \%$ de Intereconomía muestran coocurrencia con $A b c$; el $18 \%$ de 13 Tv y el $16 \%$ confían en La Razón; el 18\% de Intereconomía confía en El Español y un $30 \%$ de Intereconomía y un $24 \%$ de 13 Tv, muestran un co-ocurrencia fuerte con OkDiario. 


\section{Co-ocurrencia entre cabeceras de prensa}

Las cabeceras de prensa muestran unas co-ocurrencias menos polarizadas en general. El $48 \%$ de los que confían en $A b c$, el $47 \%$ de La Razón y el $54 \%$ de El Español, consideran que la información sobre el COVID-19 de El País es veraz y ética. Esta co-ocurrencia es mayor entre los que confían en Eldiario.es pues un 59\% de estos confía en El País.

Entre los que muestran confianza en medios de centroderecha, también se aprecia que hay co-ocurrencia fuerte con EI Mundo. Como vemos en la figura 3, el $64 \%$ de los que confían en $A b c$, el $58 \%$ de El Español y el $57 \%$ de La Razón, lo hacen en El Mundo.

Sin embargo, entre los encuestados que afirman confiar en El País, sí se vuelve a percibir una polarización mayor, pues no consideran de calidad, la información de la prensa con una ideología contraria. Vemos como el 30\% de los que confían en El País, lo hacen en Eldiario.es y un $27 \%$ lo hacen en El Mundo, el resto de cabeceras no tienen co-ocurrencias relevantes.

Cabe destacar en este sentido que, el $47 \%$ de los que confían en La Razón, lo hacen también en $A b c$ y un $31 \%$ de OkDiario, lo hace en El Español.

\section{Co-ocurrencia entre radios y televisiones}

Con respecto a los distintos medios audiovisuales, observamos que la tendencia de agrupación que hemos visto con la prensa también se cumple entre las televisiones y radios.
Las co-ocurrencias más fuertes que plasman los resultados son los siguientes: el $44 \%$ de los que confían en la información de la SER, lo hacen en La Sexta; el $44 \%$ de los que afirman confiar en la COPE y el $41 \%$ en Onda Cero, confían en Antena 3 y el $32 \%$ de los que consideran información de calidad EsRadio también valoran positivamente Intereconomía

Cabe destacar que tanto Telecinco como Cuatro, no tienen grandes co-ocurrencias en general, por lo que podemos apreciar que no se perciben sus líneas ideológicas tan claramente como ocurre con otros medios.

\section{Preferencia de consumo de medios internacionales}

Finalmente, y para contestar a la segunda variable dependiente, vemos que hay una correlación importante entre el nivel de estudios y las personas que se informan en medios extranjeros, como podemos ver en la figura 4.

Un $31 \%$ de los encuestados con doctorado, afirmaron consultar medios internacionales, siendo los más recurrentes: BBC, The New York Times, The Guardian y Le Monde.

En este sentido no se han encontrado resultados significativos del consumo de medios internacionales relacionados con la variable independiente de edad, pues la media de los que encuestados que los consume ronda el $20 \%$ en todos los grupos.

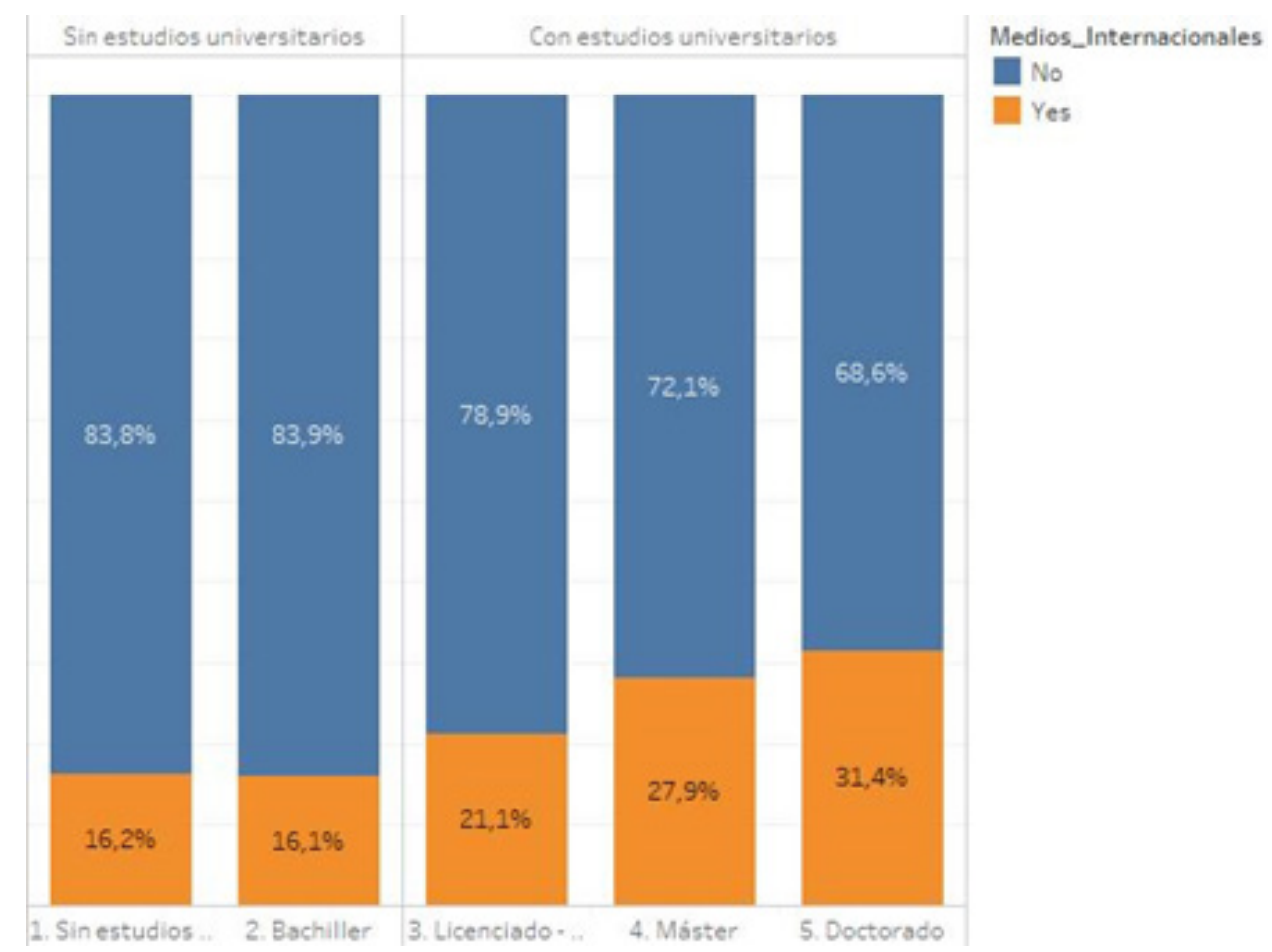

Figura 4. Consumo de medios extranjeros según nivel de estudios. Fuente: Elaboración propia. 


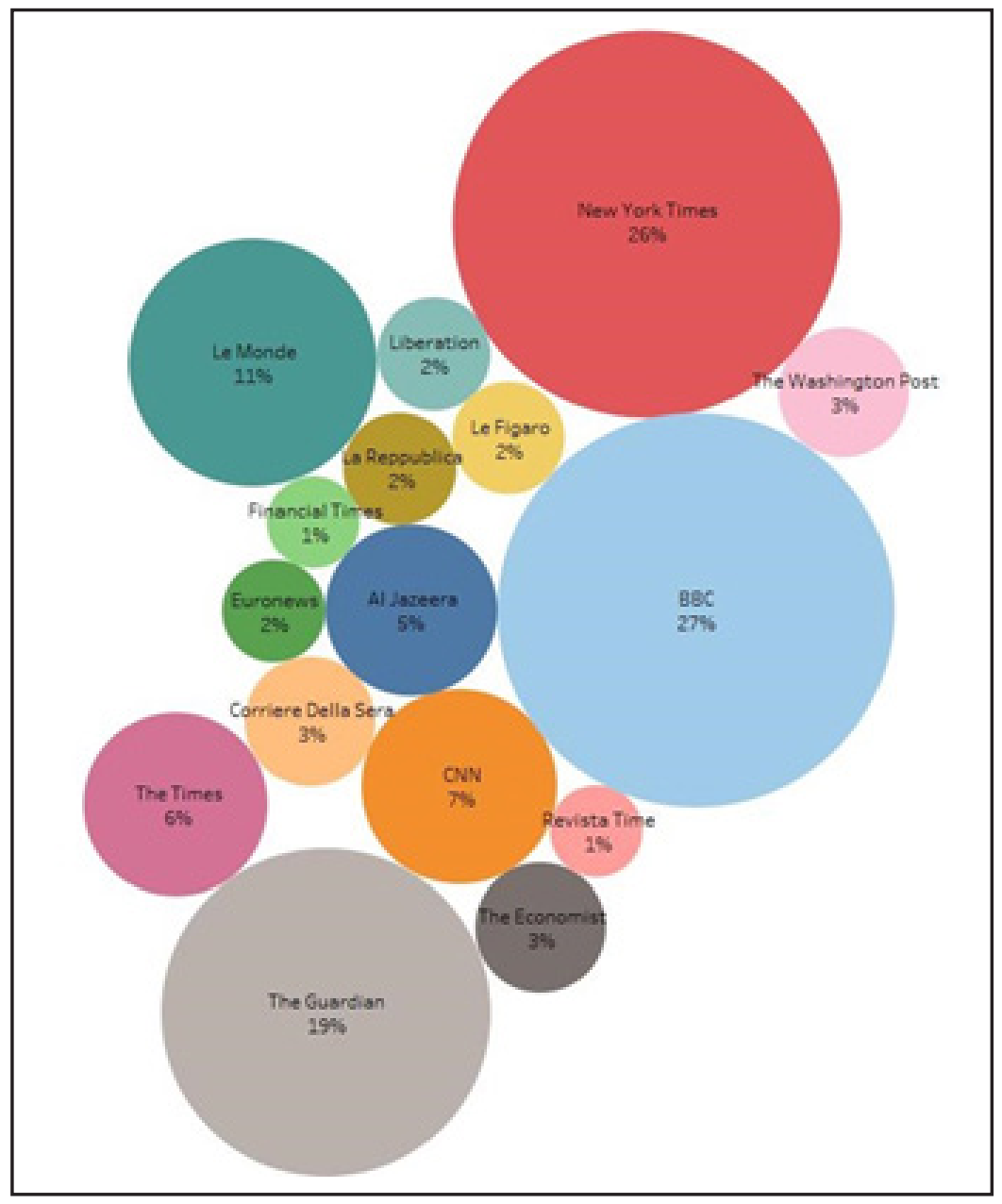

Figura 5. Medios extranjeros más consumidos. Fuente: Elaboración propia.

\section{Discusión}

Tras la llegada de Internet, los hábitos informativos pasaron de estar dominados por los medios tradicionales, a una composición de distintos mensajes informativos, ya sean audiovisuales o textuales, que se combinan en un menú informativo gracias a las plataformas digitales (Moguillansky, Ollari, \& Rodríguez, 2016).

La nueva sociedad en red y la digitalización en el sector de la información han producido un cambio en el ecosistema mediático y por ende en cómo los medios influyen en las percepciones, la comprensión, los sentimientos y los valores humanos (Canavilhas, 2011), por lo que es interesante conocer los hábitos de consumo durante una situación sin precedentes, como la que hemos vivido durante el confinamiento.

La polarización política es un fenómeno creciente y su afectación al consumo de medios es uno de los ejes de la presente investigación. Carothers y O'Donohue recomiendan para superar este problema, que asocian a la aparición de determinados liderazgos que potencian la controversia sobre identidades nacionales, el refuerzo de las instituciones y del Estado de Derecho (2019, p. 268). España se encuentra en el grupo de países más polarizados políticamente del mundo.

En cuanto a la confianza en las distintas plataformas donde informarse, el estudio muestra una mayor confianza en la televisión en los encuestados con menor nivel de estudios, mientras que la radio y la prensa son más confiables entre los de mayor nivel de formación. Sin embargo, las redes sociales se muestran transversales en este sentido.

Cabe destacar que los servicios de mensajería privados como WhatsApp, gozan de mayor confianza en encuestados con estudios superiores, en detrimento de los que no los tienen. Por otro lado, si tenemos en cuenta la variable independiente edad, los resultados indican que los encuestados de menor edad han afirmado confiar menos en este tipo de canales de comunicación que los de mayor edad.

Se aprecia una correlación entre medios que se pueden considerar más extremos dentro de ambas ideologías. Eldiario.es muestra una co-ocurrencia fuerte con La Sexta, mientras OkDiario la tiene con Intereconomía, 
mostrando que son los medios más alejados dentro del espectro formado por estos dos grupos ideológicos. Este hecho, muestra como hay una polarización estratificada dependiendo del menú mediático en el que han confiado los encuestados para informarse sobre el coronavirus.

\section{Conclusiones}

Los perfiles de consumo de medios que hemos podido correlacionar, muestran que la confianza en determinados medios tiene co-ocurrencias con otros de una línea editorial similar. Estas relaciones, reveladas en estudios anteriores, se han mantenido durante el confinamiento. Los encuestados han valorado como veraz la información sobre el coronavirus que han dado los medios mostrando un patrón de co-ocurrencia claro en dos grupos: los medios con una línea editorial de centro-izquierda y los de centro-derecha.

Una importante conclusión del presente estudio es la relación entre una polarización política cada vez más acrecentada en España y su consecuente reflejo en los medios, en lo que podríamos denominar polarización mediática. La crisis del COVID-19 y la acción política proyectada en los medios, confirma un aumento de la polarización política y mediática.

Estas correlaciones nos plantean preguntas para futuras investigaciones sobre todo para los medios públicos ya que estos pueden ser percibidos, dependiendo del partido que gobierne, como un medio de izquierdas o de derechas. En este caso, los lectores de El País, Eldiario.es, SER han percibido la información sobre el COVID-19 de TVE o RNE como veraz y ética en mayor medida que los que confiaban en medios asociados con una ideología de derechas como: Abc, El Mundo, La Razón o COPE. Teniendo en cuenta que actualmente gobierna en España una coalición de izquierdas (PSOEUnidas Podemos) esto puede influir en las percepciones sobre el ente RTVE.

\section{Referencias bibliográficas}

Alonso, P., \& Urrutia, G. (2015). ¿Dónde encontrar información epidemiológica fiable? In G. Casino, \& E. Fernández, Epidemiología para periodistas y comunicadores (pp. 57-66). Barcelona: Fundación Dr. Antonio Esteve. Recuperado de https://esteve. org/wp-content/uploads/2018/01/13109.pdf

Arias Bohigas, P. (2009). La ética durante las crisis sanitarias: a propósito de la pandemia por el virus H1N1. Revista Española de Salud Pública, 83(4), 489-491. Recuperado de http://scielo.isciii.es/ pdf/resp/v83n4/editorial.pdf
Boix, A., de la Sierra, S., Guichot, E., \& Manfredi, J. L. (2020). Hacia un modelo de regulación para garantizar la independencia de las televisiones públicas en España. Cuadernos 27, 5-31. Recuperado de https://www.circulocivicodeopinion.es/wp-content/ uploads/2020/04/Cuadernos27.pdf

Canavilhas, J. (2011). El nuevo ecosistema mediático. Index Comunicación, 1(1), 13-24. Recuperado de https://journals.sfu.ca/indexcomunicacion/index.php/ indexcomunicacion/article/view/4/16

Carothers, T., \& O'Donohue, A. (2019). Democracies Divided: The Global Challenge of Political Polarization. Washington D.C.

Casero-Ripollés, A. (2020). Impacto del Covid-19 en el sistema de medios. Consecuencias comunicativas y democráticas del consumo de noticias durante el brote. El profesional de la informacion, 29(2). doi:https://doi.org/10.3145/epi.2020.mar.23

Casino, G. (2015). Epidemiología y periodismo: encuentros y desencuentros. In G. Casino, \& E. Fernández, Epidemiología para periodistas y comunicadores (pp. 1-10). Barcelona: Fundación Dr. Antonio Esteve. Recuperado de https://esteve. org/wp-content/uploads/2018/01/13109.pdf

De Miguel, J. C., \& Pozas, V. (2009). ¿Polarización ideológica 0 económica? Relaciones entre los medios y el poder político y corporativo. Viento Sur, 103, 43-52. Recuperado de https://www.vientosur. info/spip.php?article3015

Echobox. (2020, 23 de marzo). How coronavirus has changed the face of news in less than 30 days. Recuperado de Medium: https://medium.com/ echobox/how-coronavirus-has-changed-the-face-ofnews-in-less-than-30-days-82ca1238c516

González-Esteban, J. L. (2010). Auge y caída de Soitu, un ejemplo de medio nativo digital en España. Comunicación y Sociedad, 23(2), 267-288. Recuperado de https://revistas.unav.edu/index.php/ communication-and-society/article/view/36241

Humanes, M. L. (2014). Exposición selectiva y partidismo de las audiencias en España: El consumo de información política durante las campañas electorales de 2008 y 2011. Palabra Clave, 17(3), 773-802. doi:http://dx.doi.org/10.5294/pacla.2014.17.3.9

Humanes, M. L., Martínez, M., \& Saperas, E. (2013). Political journalism in Spain: Practices, roles and 
attitudes. Estudios del mensaje periodístico, 19(2), 715-731. doi:10.5209/rev_ESMP.2013.v19. n2.43467

Innerarity, D., \& Colomina, C. (2020). Introducción: desinformación y poder, la crisis de los intermediarios. CIDOB d'Afers Internacionals, (124), 7-10. doi:doi. org/10.24241/rcai.2020.124.1.7

Jomini Stroud, N. (2010). Polarization and Partisan Selective Exposure. Journal of Communication, 60(3), 556-576. doi:https://doi.org/10.1111/j.14602466.2010.01497.x

López-Rico, C. M. (2012). Pluralismo en programas informativos de Canal9 y La1 en las elecciones de 2011. Elche: Universidad Miguel Hernández. Recuperado de https://issuu.com/carmenmarialr/ docs/tesis_pluralismo_la1_canal9_elecciones_2011

Moguillansky, M., Ollari, M. A., \& Rodríguez, G. (2016). Nuevos hábitos informativos: reflexiones teórico-metodológicas a partir del auto-análisis. IX Jornadas de Sociología de la Universidad Nacional de La Plata. Ensenada: Facultad de Humanidades y Ciencias de la Educación. Recuperado el 08 de 05 de 2020, de http://sedici.unlp.edu.ar/bitstream/ handle/10915/76684/Documento_completo.pdfPDFA.pdf?sequence=1\&isAllowed=y

Organización Panamericana de la Salud. (2020). Covid-19, consejos para informar. Guia para periodistas. Washington: Organización Panamericana de la Salud. Recuperado de https:// www.paho.org/es/documentos/covid-19-consejospara-informar-guia-para-periodistas

Porta, M. (2015). ¿Será verdad? Sobre causalidad, confusiones y sesgos. $Y$ sobre prisas, prejuicios y otras querencias. In G. Casino, \& E. Fernández, Epidemiología para periodistas y comunicadores (pp. 23-32). Barcelona: Fundación Dr. Antonio Esteve. Retrieved 05 01, 2020, from https://esteve. org/wp-content/uploads/2018/01/13109.pdf

Rosich, L., Morales, P., \& Bosch, F. (2007). Boletín REAP. REAP, 4(3). Recuperado de https://www.reap.es/ boletin/25_BOLETINREAP2007_JUL_SEP.pdf

The New Tech Observatory. (n.d.). The New Tech Observatory. Recuperado de https:// newtechobservatory.com/ponente/fran-llorente/ 